\title{
Opinions of Primary Care Clinicians and Psychiatrists on Monitoring the Metabolic Effects of Antipsychotics
}

\author{
Christina Mangurian, MD, MAS, Aishat Giwa, MHI, Erin Brosey, MS, \\ Martha Shumway, PhD, James Dilley, MD, Elena Fuentes-Afflick, MD, MPH, \\ Eliseo J. Pérez-Stable, MD, and Dean Schillinger, MD
}

Objective: Although people with severe mental illness (SMI) have high rates of diabetes and other metabolic disorders, adherence to recommended screening guidelines is low. This study aimed to compare primary care clinicians' and psychiatrists' attitudes toward metabolic monitoring and treatment of patients with SMI.

Methods: Primary care clinicians and psychiatrists within 1 large urban integrated public health system were recruited to participate in this online survey study. Multivariate logistic regression analyses were used to examine if clinician characteristics were associated with attitudes or perceived barriers toward metabolic monitoring and treatment.

Results: Response rates were 77\% (164/214) of primary care providers and 69\% (56/81) of psychiatrists completing the survey. There were no significant differences in age or race/ethnicity between provider groups, although primary care clinicians were more likely to be women when compared with the psychiatrists $(69 \%$ vs $39 \%, P<.001)$. Psychiatrists were more likely than primary care clinicians to believe that psychiatrists should conduct metabolic monitoring even if patients had a primary care provider $(80 \%$ vs $60 \%, P=.011)$ However, fewer psychiatrists than primary care clinicians believed that psychiatrists should treat identified cardiometabolic abnormalities $(15 \%$ vs $42 \%, P<.001)$.

Conclusion: Systemic problems with care coordination and these varying expectations likely contribute to poor cardiometabolic outcomes in this vulnerable population. (J Am Board Fam Med 2019;32: 418-423.)

Keywords: Diabetes Mellitus, Logistic Regression, Mental Health, Mental Disorders, Metabolic Diseases, Primary Health Care, Psychiatry, Public Health, Surveys and Questionnaires, Vulnerable Populations

People living with severe mental illness (SMI; eg, schizophrenia and bipolar disorder) experience premature mortality and die, on average, 25 years earlier than the general population, most often from cardiovascular disease. ${ }^{1-6}$ In fact, as age expectancy increases, the gap in life expectancy between these groups may actually be widening. ${ }^{6}$

This article was externally peer reviewed.

Submitted 19 June 2018; revised 4 January 2019; accepted 5 January 2019.

From Department of Psychiatry, Weill Institute for Neurosciences, University of California, San Francisco (CM, MS, JD, AG); UCSF Philip R. Lee Institute for Health Policy Studies, University of California, San Francisco (CM); Department of Psychiatry, Northern California Institute of Research and Education, University of California, San Francisco (EB); San Francisco VA Medical Center (EB); Center for Vulnerable Populations, University of California,
In addition to multiple lifestyle risk factors, second generation antipsychotic medications can cause metabolic abnormalities, which increase cardiovascular disease risk. $^{7-11}$ In a meta-analysis, Mitchell et al (2011) found that 1 in 3 patients with schizophrenia suffer from 3 or more cardiovascular

San Francisco (CM); Department of Pediatrics, University of California, San Francisco (EF-A); National Institute on Minority Health and Health Disparities, National Institute of Health (EJP-S); Division of General Internal Medicine, Department of Medicine, University of California, San Francisco (DS).

Funding: This study was funded by a pilot grant from the Center for Aging in Diverse Communities funded by grant P30-AG15272 under the Resource Centers for Minority Aging Research program by the National Institute on Aging, National Institutes of Health (Dr. Mangurian, pilot PI; Dr. Perez-Stable, PI). In addition, Dr. Mangurian was supported 
risk factors. ${ }^{9}$ Even in first-episode patients, studies have shown increases in weight ${ }^{12-15}$ and cholesterol levels, ${ }^{12,13}$ within the first 9 to 12 months of treatment. Early screening is particularly important, as rates of metabolic syndrome seem to increase with age and duration of illness. ${ }^{9}$

Unfortunately, cardiovascular risk factors are likely to be underdiagnosed and undertreated among individuals with SMI. ${ }^{16-18}$ Even during medical or surgical hospitalizations where risk factors for cardiovascular disease, such as obesity and smoking, were identified, people with SMI received fewer diet consults and smoking cessation interventions when compared with nonpsychiatric populations. ${ }^{18}$ In addition, these people with SMI were less likely to be diagnosed with laboratory-confirmed cardiovascular risk factors than their nonpsychiatric counterparts, even when controlling for demographic variables. ${ }^{18}$

There have been national efforts to reduce cardiovascular morbidity and mortality by encouraging screening, monitoring, and treatment of people who take antipsychotic medications. ${ }^{19-22}$ The American Association of Clinical Endocrinologists include the diagnosis of schizophrenia as a risk factor for prediabetes and diabetes mellitus. ${ }^{33}$ The American Diabetes Association has even mapped out standard procedures for screening patients with SMI as part of their routine medical care. ${ }^{19}$ These guidelines recommend baseline screening and continued metabolic monitoring of body mass index,

by the National Center for Research Resources, the National Center for Advancing Translational Sciences, and the Office of the Director, National Institutes of Health (NIH), through UCSF-CTSI grant KL2 RR024130 and a NIH/ National Institute of Mental Health Career Development Award (K23MH093689). Drs. Schillinger and Fuentes-Afflick were supported by the Clinical Research Network funded through NIH/NCCR UCSF-CTSI grant UL 1 RR024131. Dr. Dean Schillinger was also supported by the National Institute of Diabetes and Digestive and Kidney Diseases for The Health Delivery Systems-Center for Diabetes Translational Research (P30DK092924). Dr. Dilley was supported by a Substance Abuse and Mental Health Services Administration grant (1H79TI024339).

Conflict of interest: Ms. Giwa is currently working as an advisory consultant at PricewaterhouseCoopers. Ms. Brosey is currently working as a Clinical Trial Associate at Aerotek, Inc. The remaining authors have no conflicting or competing interests to report. The contents and views in this manuscript are those of the authors and should not be construed to represent the views of the National Institutes of Health or any of the sponsoring organizations and agencies of the US government.

Corresponding author: Christina Mangurian, MD, MAS, 1001 Potrero Avenue, Suite 7M, San Francisco, CA 94110 (E-mail: christina.mangurian@ucsf.edu). waist circumference, blood pressure, fasting blood glucose, and fasting lipids. ${ }^{19,20}$ Despite these guidelines and psychiatrists' acknowledgment of their importance, monitoring rates continue to be low. ${ }^{23-26}$

This lack of metabolic monitoring raises the issue of accountability. Our prior work has examined the beliefs of community primary care clinicians and psychiatrists, respectively. ${ }^{27,28}$ In this article, we compare these responses from within an integrated public delivery system. To our knowledge, this is the first survey study to compare opinions of 2 key specialties regarding whose role it is, or should be, to monitor and treat metabolic abnormalities among people with SMI.

\section{Methods}

\section{Setting and Sample}

All primary care clinicians (physicians, nurse practitioners, and physician assistants) and psychiatrists were approached from safety-net clinics in 1 large urban integrated public health system. The system includes clinics operated by the public health department and by affiliated community health centers. The primary care and mental health clinics do not share electronic health records. Clinician participants were surveyed between December 2009 and February 2011.

\section{Study Procedures}

The recruitment methods for psychiatrists and primary care clinicians have been described previously. ${ }^{27,28}$ Briefly, clinicians were offered an opportunity to participate in an anonymous survey about metabolic monitoring of people taking antipsychotic medications. Potential participants were contacted by a research coordinator and asked to complete a survey either on article or online. The survey was distributed to the psychiatrists first and was adapted for the primary care clinician sample. To meet inclusion criteria, a provider must have (1) primarily treated adults and (2) spent $5 \%$ or more of their time in direct patient care. A \$5 gift card was offered to all respondents regardless of survey completion. Follow-up e-mails were sent 2 weeks after initial survey distribution. Study procedures were approved by the University of California, San Francisco Committee on Human Research (number 10-03254). 


\begin{tabular}{|c|c|c|c|c|c|c|c|c|}
\hline \multirow[b]{4}{*}{ Statement } & \multicolumn{8}{|c|}{ Provider Type* } \\
\hline & \multicolumn{4}{|c|}{ Psychiatrists } & \multicolumn{4}{|c|}{ Primary Care Clinicians } \\
\hline & \multicolumn{2}{|c|}{ Disagree } & \multicolumn{2}{|c|}{ Agree } & \multicolumn{2}{|c|}{ Disagree } & \multicolumn{2}{|c|}{ Agree } \\
\hline & $\mathrm{N}$ & $\%$ & $\mathrm{~N}$ & $\%$ & $\mathrm{~N}$ & $\%$ & $\mathrm{~N}$ & $\%$ \\
\hline $\begin{array}{l}\text { Primary care clinicians should screen not } \\
\text { psychiatrists }^{\dagger}\end{array}$ & 30 & 70 & 14 & 30 & 52 & 33 & 102 & 66 \\
\hline $\begin{array}{l}\text { Psychiatrists should screen even if the patient } \\
\text { has established primary care }{ }^{\ddagger}\end{array}$ & 10 & 20 & 39 & 80 & 63 & 40 & 93 & 60 \\
\hline
\end{tabular}

*Notably, there were minor differences in the number of providers responding to these questions. For example, 47 psychiatrists and 154 primary care clinicians answered the first statement and 49 psychiatrists and 156 primary care clinicians answered the second. ${ }^{+}$Primary care clinicians were more likely than psychiatrists to agree with this statement $(P<.001)$.

${ }^{\ddagger}$ Psychiatrists were more likely than primary care clinicians to agree with this statement $(P=.011)$.

\section{Measures}

In addition to clinician demographic and practice questions, ${ }^{29,30}$ the survey included questions about perceived roles of providers in metabolic monitoring and/or treatment of metabolic abnormalities and barriers to metabolic monitoring of patients on antipsychotic medications. Questions were drawn from the literature and expert consultation as described previously. ${ }^{23,24,27-30}$

Attitudes about roles were rated on a 5 -point Likert scale. Because responses were skewed, these were reduced to: (1) "Disagree" (including "strongly disagree," "disagree," and "neutral" responses), and (2) "Agree" (including "agree" and "strongly agree" responses).

Respondents were asked to identify the 1 "top barrier" that had the largest impact on metabolic screening from 25 possibilities. Questions about care coordination were collapsed into 1 category ("Difficulty with care coordination"). The survey is publicly available online (https://www.ncbi.nlm. nih.gov/pmc/articles/PMC3780562/).

\section{Data Analysis}

The $t$ tests and $\chi^{2}$ tests were used to determine if any clinician demographic characteristics were related to attitudes toward metabolic monitoring or treatment. Multivariate logistic regression analysis was used to examine if clinician characteristics might be associated with attitudes toward metabolic monitoring and treatment. Logistic regressions were used to determine whether clinician characteristics were associated with perceived barriers to metabolic monitoring.

\section{Results}

All 81 psychiatrists in this urban safety-net public health system were approached to participate; $69 \%$ (56/81) responded and 86\% (49/56) of these met inclusion criteria. All 214 primary care clinicians in this urban safety-net public health system were approached to participate; $77 \%(164 / 214)$ of primary care clinicians responded and 98\% (160/164) of these met inclusion criteria. Most primary care clinicians were physicians $(62 \%, 99 / 160)$, whereas $36 \%(57 / 160)$ were nurse practitioners and $2 \%$ (4/160) were physician's assistants.

In terms of demographic information, the primary care clinicians were more likely than psychiatrists to be women ( $69 \%$ vs $39 \%, P<.001)$, but otherwise there were no significant differences between providers in age or race/ethnicity. In addition, there were no significant differences in opinions between medical doctor primary care clinicians and non-medical doctor clinicians for the questions highlighted below.

When asked about monitoring metabolic risk factors, clinicians were asked about specific circumstances. For example, most primary care providers $(66 \%, 102 / 154)$ believed that "primary care providers, not psychiatrists," should monitor metabolic risk in contrast to only $30 \%(14 / 47)$ of psychiatrists $(P<.001, t=4.637, \mathrm{df}=199)($ Table 1$)$.

A significant proportion of both primary care clinicians $(60 \%, 93 / 156)$ and psychiatrists $(80 \%$, 39/49) agreed that the "psychiatrist or mental health clinic, even if patients have established primary care" should monitor for metabolic risk factors, with psychiatrists believing this even more 
strongly $(P=.011, t=-2.576 \mathrm{df}=203)($ Table 1$)$. In contrast, less than half of primary care providers $(42 \%, 66 / 158)$ and fewer psychiatrists $(15 \%, 7 / 48)$ believed that the psychiatrists' role is to "prescribe oral medications to treat elements of metabolic dysfunction (eg, statins...)," with a significantly lower proportion of psychiatrists believing that they should play this role $(P<.001, t=3.536, \mathrm{df}=$ 204).

Sixty percent (114/191) of both clinician groups reported either severity of mental illness or difficulty with care coordination as 2 barriers. There were no significant differences in reported "top barriers" between the psychiatrists and primary care clinicians. Insufficient provider time, insufficient staff availability, and difficulty accessing laboratory data were reported by close to $20 \%$ of providers overall as key barriers.

\section{Discussion}

To our knowledge, this is the first study to compare psychiatrists' and primary care clinicians' opinions on provider and system-level factors that affect monitoring and treatment of metabolic abnormalities among people with SMI. Understanding clinicians' anticipated role in screening for these risk factors is a key component to increasing the rate at which patients with SMI receive medical treatment for these symptoms.

Our findings suggest a sizable disconnect between where (and by whom) clinicians believe metabolic monitoring should be done and where (and by whom) treatment should be initiated. Despite endorsing the practicality of psychiatrists monitoring metabolic abnormalities, a majority of clinicians in both groups believed that the treatment of metabolic dysfunctions is the role of the primary care clinician exclusively. This disconnect between where monitoring and treatment should occur undoubtedly contributes to the poor rates of treatment for metabolic abnormalities among this vulnerable population.

Despite initiatives to improve cardiometabolic screening and treatment among people with SMI, ${ }^{19-22}$ they are still woefully underscreened ${ }^{26}$ while being at greater risk for early mortality compared with the general population. Part of this problem-as highlighted in this study-is lack of ownership over who should be doing the screening. One solution to this potential lack of coordinated care among providers could involve colocating pri- mary care clinicians in community mental health care settings. A study by McGinty et al (2015) indicates veterans with SMI tend to receive better comprehensive medical care in the Veterans Health Administration, which offers multiple providers at 1 location and includes a nationwide network of electronic medical records that assist with patient care. They found that compared with Veterans Health Administration patients, Medicaid patients had the lowest adherence to national guidelines on medical care and screening over time. ${ }^{31}$ Integrated health care systems provide the greatest ability to coordinate patient care but are costly and difficult to implement nation-wide. ${ }^{32}$ Therefore, it may be worth considering having on-site physicians at community mental health clinics (the psychiatrists) perform metabolic monitoring and initiating firstline treatment for relatively easy to treat metabolic abnormalities (eg, dyslipidemia). This could be facilitated through a standardized consultation with a designated primary care physician.

This study's primary limitation is that it relies on a single urban community safety-net health system. In addition, the clinicians were not asked to choose between specific clinician groups in questions regarding monitoring or treatment, making findings of role preferences less than definitive. Although these aspects are beyond the scope of this article, we believe this study is an important first step in qualifying the role psychiatrists and primary care physicians play in the identification and treatment of metabolic and cardiovascular risk factors in patients with SMI.

The authors thank Nicholas S. Riano, MAS, for his assistance in the preparation and submission of this manuscript.

To see this article online, please go to: http://jabfm.org/content/ 32/3/418.full.

\section{References}

1. Colton CW, Manderscheid RW. Congruencies in increased mortality rates, years of potential life lost, and causes of death among public mental health clients in eight states. Prev Chronic Dis. 2006;3:A42.

2. Brown S, Kim M, Mitchell C, Inskip H. Twenty-five year mortality of a community cohort with schizophrenia. Br J Psychiatry. 2010;196:116-121.

3. Walker ER, McGee RE, Druss BG. Mortality in mental disorders and global disease burden implications: a systematic review and meta-analysis. JAMA Psychiatry. 2015;72:334-341. 
4. Olfson M, Gerhard T, Huang C, Crystal S, Stroup TS. Premature mortality among adults with schizophrenia in the United States. JAMA Psychiatry. 2015;72:1172-1181.

5. Lawrence D, Hancock KJ, Kisely S. The gap in life expectancy from preventable physical illness in psychiatric patients in Western Australia: retrospective analysis of population based registers. BMJ. 2013; 346:f2539.

6. Laursen TM, Nordentoft M, Mortensen PB. Excess early mortality in schizophrenia. Ann Rev Clin Psychol 2014;10:425-48.

7. McEvoy JP, Meyer JM, Goff DC, et al. Prevalence of the metabolic syndrome in patients with schizophrenia: baseline results from the Clinical Antipsychotic Trials of Intervention Effectiveness (CATIE) schizophrenia trial and comparison with national estimates from NHANES III. Schizophr Res. 2005;80:19-32.

8. Newcomer JW, Hennekens CH. Severe mental illness and risk of cardiovascular disease. JAMA. 2007; 298:1794-1796.

9. Mitchell AJ, Vancampfort D, Sweers K, van Winkel R, Yu W, De Hert M. Prevalence of metabolic syndrome and metabolic abnormalities in schizophrenia and related disorders-a systematic review and metaanalysis. Schizophr Bull. 2013;39:306-318.

10. Correll CU, Joffe BI, Rosen LM, Sullivan TB, Joffe RT. Cardiovascular and cerebrovascular risk factors and events associated with second-generation antipsychotic compared to antidepressant use in a nonelderly adult sample: results from a claims-based inception cohort study. World Psychiatry. 2015;14: 56-63.

11. Vancampfort D, Stubbs B, Mitchell AJ, et al. Risk of metabolic syndrome and its components in people with schizophrenia and related psychotic disorders, bipolar disorder and major depressive disorder: a systematic review and meta-analysis. World Psychiatry. 2015;14:339-347.

12. Green AI, Lieberman JA, Hamer RM, et al. Olanzapine and haloperidol in first episode psychosis: two-year data. Schizophr Res. 2006;86:234-243.

13. Kahn RS, Fleischhacker WW, Boter H, et al. Effectiveness of antipsychotic drugs in first-episode schizophrenia and schizophreniform disorder: an open randomised clinical trial. Lancet. 2008;371: 1085-1097.

14. Perez-Iglesias R, Mata I, Pelayo-Teran JM, et al. Glucose and lipid disturbances after 1 year of antipsychotic treatment in a drug-naive population. Schizophr Res. 2009;107:115-121.

15. Oriot P, Feys JL, Mertens de Wilmars S, et al. Insulin sensitivity, adjusted beta-cell function and adiponectinaemia among lean drug-naive schizophrenic patients treated with atypical antipsychotic drugs: a nine-month prospective study. Diabetes Metab. 2008;34:490-496.
16. Nasrallah HA, Meyer JM, Goff DC, et al. Low rates of treatment for hypertension, dyslipidemia and diabetes in schizophrenia: data from the CATIE schizophrenia trial sample at baseline. Schizophr Res. 2006;86:15-22.

17. Smith DJ, Langan J, McLean G, Guthrie B, Mercer SW. Schizophrenia is associated with excess multiple physical-health comorbidities but low levels of recorded cardiovascular disease in primary care: cross-sectional study. BMJ Open. 2013; 3:e002808.

18. Briskman I, Bar G, Boaz M, Shargorodsky M. Impact of co-morbid mental illness on the diagnosis and management of patients hospitalized for medical conditions in a general hospital. Int J Psychiatry Med 2012;43:339-48.

19. Citrome L, Volavka J. Consensus development conference on antipsychotic drugs and obesity and diabetes: response to consensus statement. J Clin Psychiatry. 2005;66:1073-1074.

20. Parks J, Radke A.Q., Mazade, N.A. Measurement of health status for people with serious mental illness. Alexandria, VA: National Association of State Mental Health Program Directors; 2008.

21. Green CA, Yarborough BJ, Leo MC, et al. The STRIDE weight loss and lifestyle intervention for individuals taking antipsychotic medications: a randomized trial. Am J Psychiatry. 2015;172:71-81.

22. Daumit GL, Dickerson FB, Wang NY, et al. A behavioral weight-loss intervention in persons with serious mental illness. N Engl J MEd. 2013; 368:1594-1602.

23. Buckley PF, Miller DD, Singer B, Arena J, Stirewalt EM. Clinicians' recognition of the metabolic adverse effects of antipsychotic medications. Schizophr Res. 2005;79:281-288.

24. Essock SM, Covell NH, Leckman-Westin E, et al. Identifying clinically questionable psychotropic prescribing practices for Medicaid recipients in New York state. Psychiatr Serv. 2009;60:15951602.

25. Morrato EH, Druss B, Hartung DM, et al. Metabolic testing rates in 3 state Medicaid programs after FDA warnings and ADA/APA recommendations for second-generation antipsychotic drugs. Arch Gen Psychiatry. 2010;67:17-24.

26. Mangurian C, Newcomer JW, Vittinghoff E, et al. Diabetes screening among underserved adults with severe mental illness who take antipsychotic medications. JAMA Intern Med. 2015;175:1977-1979.

27. Mangurian C, Giwa F, Shumway M, et al. Primary care providers' views on metabolic monitoring of outpatients taking antipsychotic medication. Psychiatr Serv. 2013;64:597-599.

28. Parameswaran SG, Chang C, Swenson AK, Shumway M, Olfson M, Mangurian CV. Roles in and barriers to metabolic screening for people taking 
antipsychotic medications: a survey of psychiatrists. Schizophr Res. 2013;143:395-396.

29. Arbuckle MR, Gameroff MJ, Marcus SC, West JC, Wilk J, Olfson M. Psychiatric opinion and antipsychotic selection in the management of schizophrenia. Psychiatr Services. 2008;59:561-565.

30. Olfson M, Marcus SC, Wilk J, West JC. Awareness of illness and nonadherence to antipsychotic medications among persons with schizophrenia. Psychiatr Serv. 2006;57:205-211.

31. McGinty EE, Baller J, Azrin ST, Juliano-Bult D, Daumit GL. Quality of medical care for persons with serious mental illness: a comprehensive review. Schizophr Res. 2015;165:227-235.

32. Amiel JM, Pincus HA. The medical home model: new opportunities for psychiatric services in the United States. Curr Opin Psychiatry. 2011;24:562568.

33. Handelsman Y, Bloomgarden ZT, Grunberger G, et al. American Association of Clinical Endocrinologists and American College of Endocrinology-clinical practice guidelines for developing a diabetes mellitus comprehensive care plan-2015. Endocrine Practice. 2015;21.s1:1-87. 


\section{APPENDIX: Primary Care Providers Questionnaire}

Date $(\mathrm{dd} / \mathrm{mm} / \mathrm{yy})$ :

\section{Basic Information:}

1. Age

2. Gender: $\quad \square$ Male $\quad \square$ Female

3a. Ethnicity: $\quad \square$ Hispanic or Latino/Latina $\quad \square$ Non Hispanic or Latino/Latina

3b. Race: (select all that apply)

$\square$ American Indian or Alaska Native

$\square$ Native Hawaiian or Other Pacific Islander

$\square$ Asian $\quad \square$ Black or African American

$\square$ White $\quad \square$ Other:

\section{Provider Characteristics:}

4. What type of provider are you: $\square$ Physician $\quad \square$ Nurse Practitioner $\quad \square$ Physician Assistant 4a. Are more than $50 \%$ of your clients adults (>18y/o)? $\quad \square$ Yes $\square$ No (If no, please stop survey)

5. In training (residency, fellowship, or other)? $\quad \square$ Yes $\square$ No (If no, please skip to question \#6) 5a. Specify type of training program (e.g., internal medicine, nurse practitioner):

5b. Year of graduation from training:

6. Approximate percentage (\%) of time per week is spent in the following practice settings:

Private practice

Hospital setting

Outpatient primary care clinic

Research (circle which applies: lab/clinic)

TOTAL

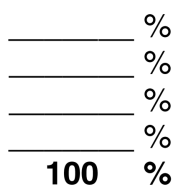

7. Which clinic(s) do you work in? (Please select all that apply):

List of San Francisco Community Clinics

8. Approximate percentage (\%) of patients in your clinic having the following primary source of insurance:

Privately insured

Publicly insured (e.g., Medicaid, Medicare)

Self-pay (able to pay)

Uninsured

TOTAL

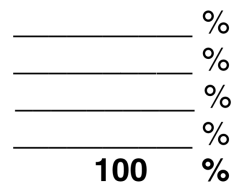

9. Total number of unique outpatients you saw across all practice settings in the last month:

10. Approximate percentage (\%) of your patients with the following primary psychiatric diagnoses:

Schizophrenia or schizoaffective disorder

Bipolar I or II disorder

Major depression or other depression

Other Psychiatric Diagnosis

TOTAL

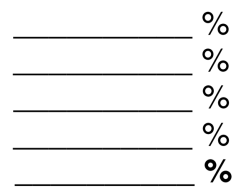

$\rightarrow$ Continue 
APPENDIX: Primary Care Providers Questionnaire

11. Approximate percentage of these psychiatric patients that are being prescribed antipsychotic medications at risk for causing metabolic dysfunction, such as increased BMI, obesity, and diabetes (e.g. olanzapine,

risperdone, chlorpromazine): $\%$

12. Are you aware of the ADA/APA (American Diabetes Association, American Psychiatric Association) consensus statement describing metabolic risks associated with second generation antipsychotic medications and specifying a monitoring protocol for patients taking these medications?

$$
\text { YES NO }
$$

\section{Physician Attitudes:}

For each question, please circle the choice that best fits your response:

13. How strongly do you agree or disagree with the following statements?

a. Individuals with schizophrenia are more at risk than the general population for suffering metabolic dysfunction, such as increased BMI, obesity, and diabetes.

Strongly disagree Disagree Neutral Agree Strongly agree

b. Some antipsychotic medications can contribute to metabolic dysfunction, such as increased BMI, obesity, and diabetes.

Strongly disagree Disagree Neutral Agree Strongly agree

\section{Physician Roles:}

For each question, please circle the choice that best fits your response:

Roles in Monitoring:

14. How strongly do you agree or disagree with the following statements?

Monitoring metabolic risk factors (such as BMI, BP, glucose, and/or lipids) in patients on antipsychotics at risk of causing metabolic dysfunction is the role of:

a. Primary care providers, not psychiatrists or mental health clinics.

$$
\text { Strongly disagree Disagree Neutral Agree Strongly agree }
$$

b. The psychiatrist or mental health clinic, only if patients do not have an established primary care provider.

Strongly disagree Disagree Neutral Agree Strongly agree

c. The psychiatrist or mental health clinic, even if patients have established primary care.

Strongly disagree Disagree Neutral Agree Strongly agree

\section{$\rightarrow$ Continue}


APPENDIX: Primary Care Providers Questionnaire

Roles in Treatment:

15. How strongly do you agree or disagree with the following statements about the responsibility of community psychiatrists?

If patients in a mental health clinic are found to have abnormalities in metabolic risk factors that are likely caused by treatment with antipsychotic medications, the following interventions may be the responsibility of the treating psychiatrist:

a. Responsibility of psychiatrists to refer to primary care providers or other medical follow-up

Strongly disagree Disagree Neutral Agree Strongly agree

b. Responsibility of psychiatrists to directly contact patients' primary care or other medical providers

Strongly disagree Disagree Neutral Agree Strongly agree

c. Responsibility of psychiatrists to maintain contact with primary care or other medical providers regarding continuing treatment of metabolic risk factors

Strongly disagree Disagree Neutral Agree Strongly agree

d. Responsibility of psychiatrists to provide patients with literature regarding metabolic syndrome and related metabolic risk indicators

Strongly disagree Disagree Neutral Agree Strongly agree

e. Responsibility of psychiatrists to refer patients to weight loss programs, or other related psychosocial or support group programs

Strongly disagree Disagree Neutral Agree Strongly agree

f. Responsibility of psychiatrists to refer patients to smoking cessation programs

Strongly disagree Disagree Neutral Agree Strongly agree

16. How strongly do you agree or disagree with the following statement?

a. Prescribing oral medications to treat elements of metabolic dysfunction (e.g., statins, metformin) may, in certain circumstances, be the responsibility of the outpatient treating psychiatrist.

Strongly disagree Disagree Neutral Agree Strongly agree

b. In which of the following circumstances do you think it would be appropriate to have the treating outpatient psychiatrist prescribe oral medications to treat elements of metabolic dysfunction? Please select all that apply.

$\square$ In extremely rare circumstances (e.g., patients requesting emergency refills)

$\square$ Sharing responsibility for treatment in partnership with a primary care or other medical provider

$\square$ If a patient does not have access to primary care or other medical providers

$\square$ If the psychiatrist is the sole provider treating elements of metabolic dysfunction 
APPENDIX: Primary Care Providers Questionnaire

Barriers to Monitoring:

17. In the following section, please rate the degree to which the factors listed below are significant barriers to monitoring your patients for metabolic risk. For each factor, circle one of the following that best suits your response to whether you agree or disagree that the factor is a significant barrier to monitoring: strongly disagree (1), disagree (2), neutral (3), agree (4), or strongly agree (5), or select N/A if the factor is not relevant to your patients or practice environment.

I believe the following patient factors are a barrier to monitoring patients for monitoring metabolic risk:

\begin{tabular}{|l|c|c|c|c|c|c|}
\hline & $\begin{array}{c}\text { Strongly } \\
\text { disagree }\end{array}$ & Disagree & Neutral & Agree & $\begin{array}{c}\text { Strongly } \\
\text { agree }\end{array}$ & \\
\hline Gender & 1 & 2 & 3 & 4 & 5 & N/A \\
\hline Lack of insurance & 1 & 2 & 3 & 4 & 5 & N/A \\
\hline Lack of income & 1 & 2 & 3 & 4 & 5 & N/A \\
\hline Ethnic or cultural factors & 1 & 2 & 3 & 4 & 5 & N/A \\
\hline Fluency of English & 1 & 2 & 3 & 4 & 5 & N/A \\
\hline Legal status & 1 & 2 & 3 & 4 & 5 & N/A \\
\hline Lack of education & 1 & 2 & 3 & 4 & 5 & N/A \\
\hline Severity of psychiatric illness & 1 & 2 & 3 & 4 & 5 & N/A \\
\hline
\end{tabular}

I believe the following staffing or physician factors (at your primary care clinic) are a barrier to monitoring patients for monitoring metabolic risk:

\begin{tabular}{|l|c|c|c|c|c|c|}
\hline & $\begin{array}{c}\text { Strongly } \\
\text { disagree }\end{array}$ & Disagree & Neutral & Agree & $\begin{array}{c}\text { Strongly } \\
\text { agree }\end{array}$ & N/A \\
\hline Insufficient staff availability & 1 & 2 & 3 & 4 & 5 & N/A \\
\hline Insufficient staff awareness & 1 & 2 & 3 & 4 & 5 & N/A \\
\hline Insufficient staff training & 1 & 2 & 3 & 4 & 5 & N/A \\
\hline Insufficient physician time & 1 & 2 & 3 & 4 & 5 & N/A \\
\hline $\begin{array}{l}\text { Ability to counsel this population } \\
\text { about metabolic problems }\end{array}$ & 1 & 2 & 3 & 4 & 5 & N/A \\
\hline $\begin{array}{l}\text { Ability to treat metabolic problems } \\
\text { in this population }\end{array}$ & 1 & 2 & 3 & 4 & 5 & N/A \\
\hline $\begin{array}{l}\text { Insufficient reimbursement for } \\
\text { screening }\end{array}$ & 1 & 2 & 3 & 4 & 5 & N/A \\
\hline $\begin{array}{l}\text { Insufficient reimbursement for } \\
\text { treatment }\end{array}$ & 1 & 2 & 3 & 4 & 5 & N/A \\
\hline Burden of documentation & 1 & 2 & 3 & 4 & 5 & N/A \\
\hline Difficulty accessing laboratory data & 1 & 2 & 3 & 4 & 5 & N/A \\
\hline $\begin{array}{l}\text { Medicolegal liability of testing } \\
\text { patients }\end{array}$ & 1 & 2 & 3 & 4 & & 5 \\
\hline Medicolegal liability of treatment & 1 & 2 & 3 & 4 & 5 & N/A \\
\hline
\end{tabular}

I believe the following referral and collaboration factors are a barrier to monitoring patients for monitoring metabolic risk in our health care system in San Francisco County:

\begin{tabular}{|l|c|c|c|c|c|c|}
\hline & $\begin{array}{l}\text { Strongly } \\
\text { disagree }\end{array}$ & Disagree & Neutral & Agree & $\begin{array}{l}\text { Strongly } \\
\text { agree }\end{array}$ & 5 \\
\hline $\begin{array}{l}\text { Difficulty arranging referral for psychiatric } \\
\text { follow-up }\end{array}$ & 1 & 2 & 3 & 4 & N/A \\
\hline Lack of access to psychiatric follow-up & 1 & 2 & 3 & 4 & 5 & N/A \\
\hline $\begin{array}{l}\text { Wait times for appointments for psychiatric } \\
\text { follow-up }\end{array}$ & 1 & 2 & 3 & 4 & 5 & N/A \\
\hline $\begin{array}{l}\text { Difficulty collaborating with physicians } \\
\text { providing psychiatric follow-up }\end{array}$ & 1 & 2 & 3 & 4 & 5 & N/A \\
\hline Increased cost of collaborative care & 1 & 2 & 3 & 4 & 5 & N/A \\
\hline
\end{tabular}


APPENDIX: Primary Care Providers Questionnaire

18. Please use the below list of barriers to answer the following questions:

a. Please rank numerically (with $\mathbf{1 , 2}$, and $\mathbf{3}$ ) what you think are the top $\mathbf{3}$ barriers in your practice to screening and monitoring patients on antipsychotics at risk for causing metabolic dysfunction:

_ Gender

Lack of insurance

_ Lack of income

Ethnic or cultural factors

Fluency of English

Legal status

Lack of education

Severity of psychiatric illness

_ Insufficient staff availability

_ Insufficient staff awareness

_ Insufficient staff training

_ Insufficient physician time
Ability to counsel these patients about metabolic problems

Ability to treat metabolic problems in this population

_ Insufficient reimbursement for screening

_ Insufficient reimbursement for treatment

Burden of documentation

— Difficulty accessing laboratory data

_ Medicolegal liability of testing patients

_ Medicolegal liability of treatment

_ Difficulty arranging referral for psychiatric follow-up

Lack of access to qualified psychiatric follow-up

Wait times for appointments for psychiatric follow-up

_ Difficulty collaborating with psychiatrists

_ Increased cost of collaborative care

b. If you could only choose ONE barrier from the above list of barriers that has the largest impact on screening, which would that be?

19. How strongly do you agree or disagree with the following statement?

Solving the ONE barrier I have listed above is likely to make a measurable impact in the rate of metabolic screening for patients at risk for developing metabolic dysfunction.

Strongly disagree Disagree Neutral Agree Strongly agree

Thank You! 